\title{
Rift Initiation and Evolution Recorded in the Oblique Tusas-Abiquiu Segment of the Rio Grande Rift, New Mexico
}

Yiduo Liu ${ }^{1}$

Michael A. Murphy ${ }^{1}$

Jolante van Wijk ${ }^{1,2}$ Ross A. Andrea ${ }^{1}$
1 University of Houston

2 New Mexico Tech

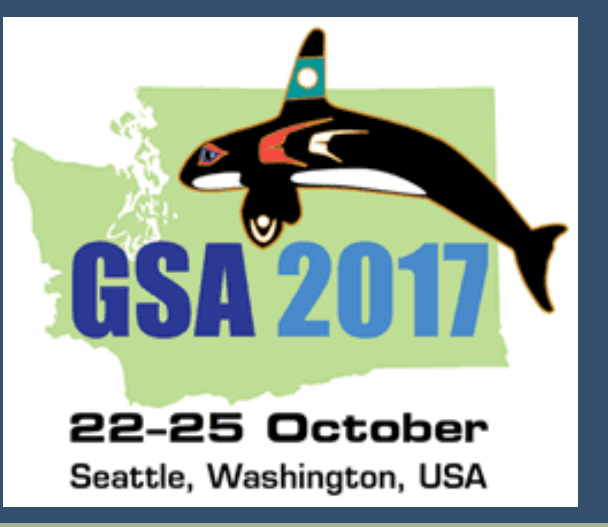




\section{Rio Grande rifting: multiphase and multi-directional}

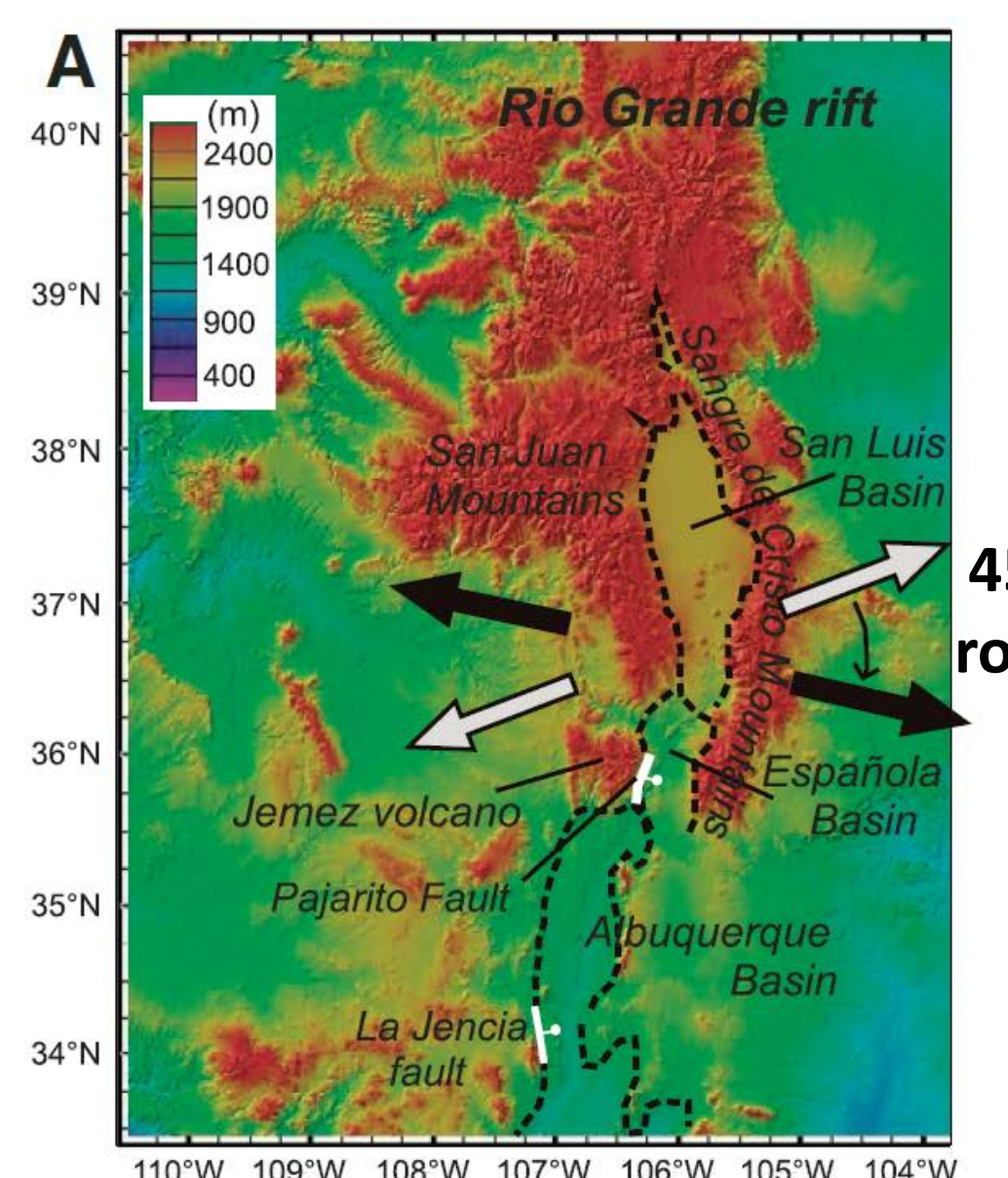

\section{B Two magma pulses \&}

extension phases

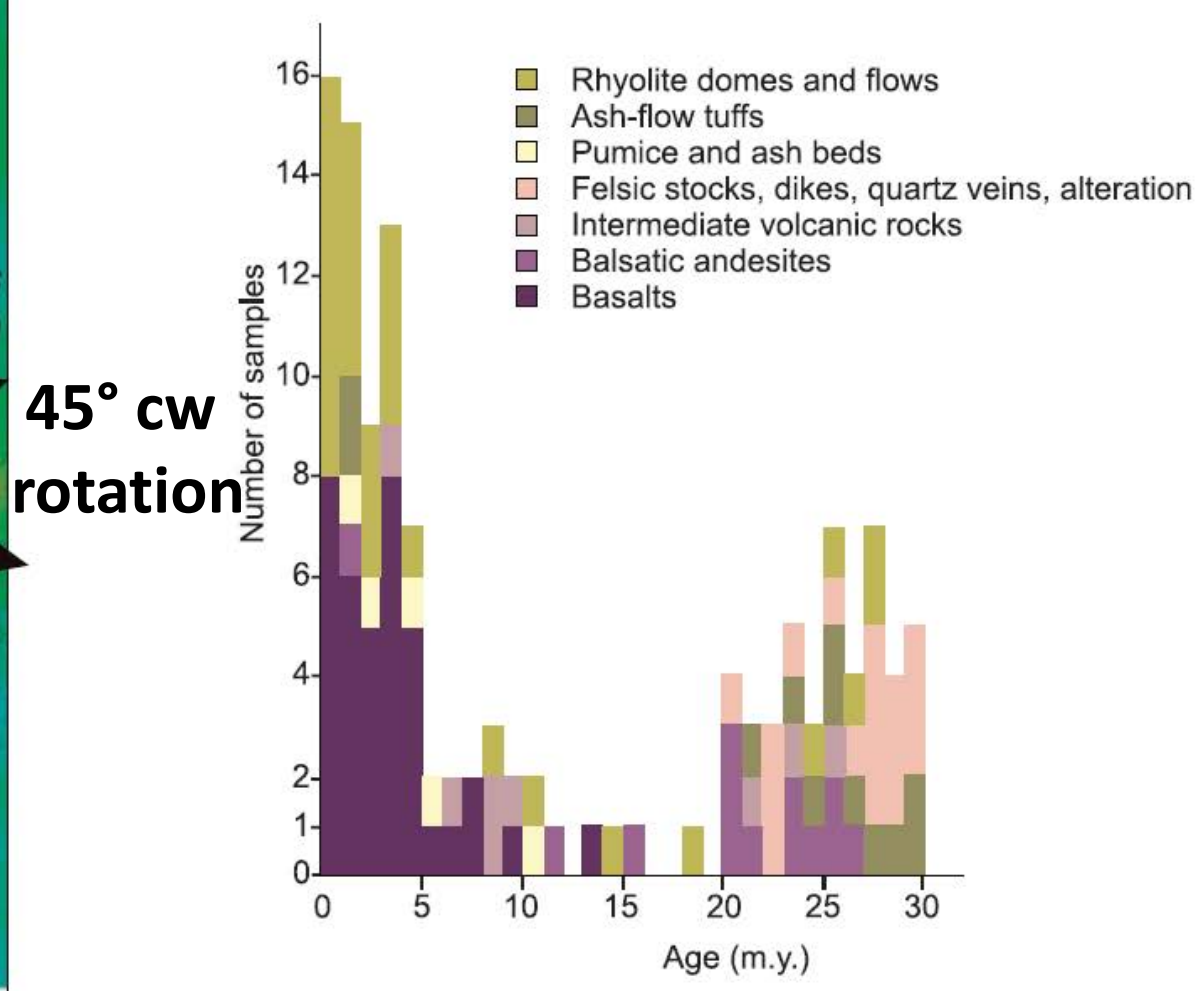

$110^{\circ} \mathrm{W} \quad 109^{\circ} \mathrm{W} \quad 108^{\circ} \mathrm{W} \quad 107^{\circ} \mathrm{W} \quad 106^{\circ} \mathrm{W} \quad 105^{\circ} \mathrm{W} \quad 104^{\circ} \mathrm{W}$

(Zoback et al., 1981; Ebinger et al., 2013) 


\section{Oligocene Extension: Basin \& Range, S RGR, and N RGR}

(a) 24-30 Ma

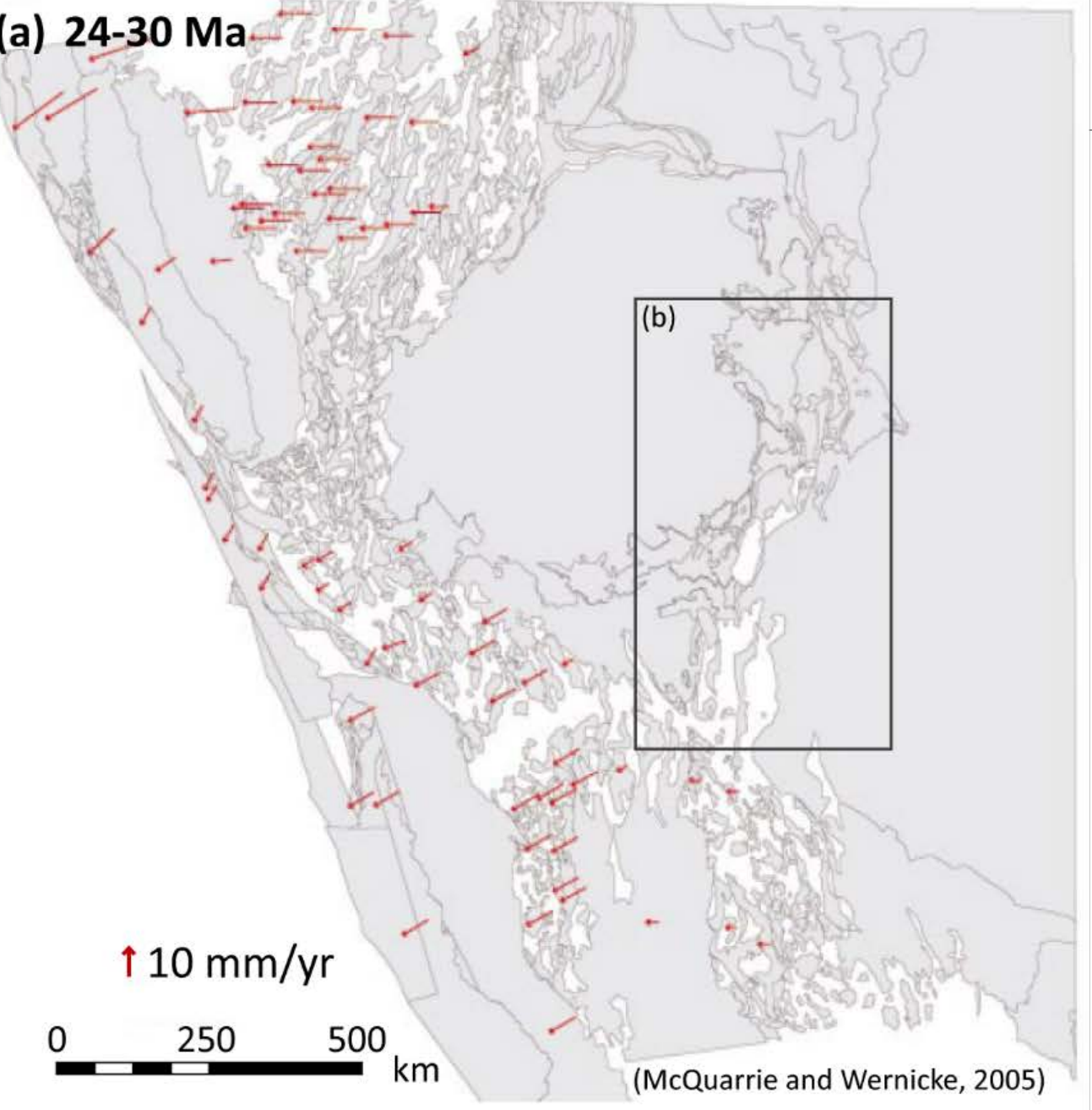

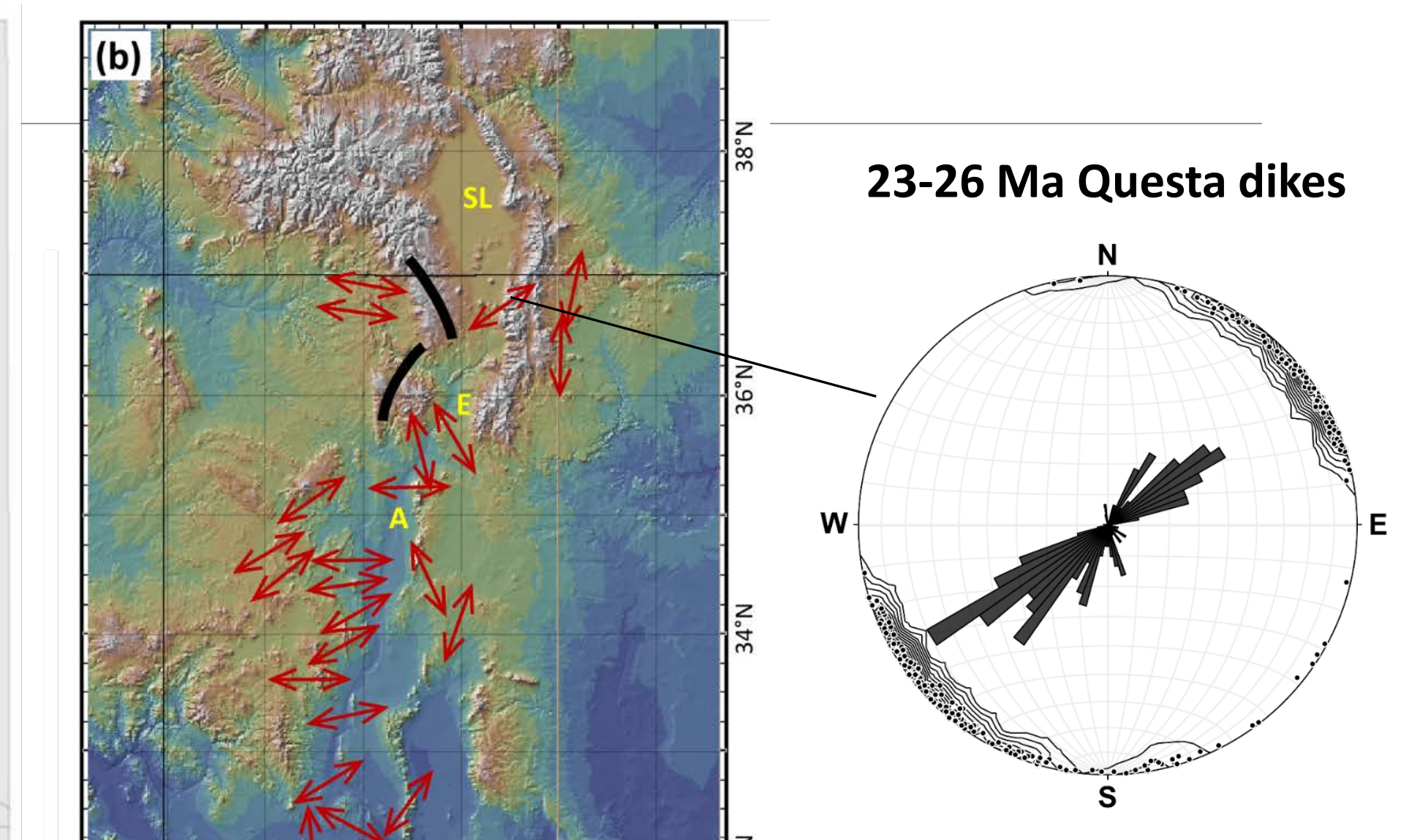

Poles, $\mathrm{n}=239$

(data from Lipman \& Reed, 1989)

Dike is not really a good indicator for the extension orientation in the N RGR... 


\section{Motivations}

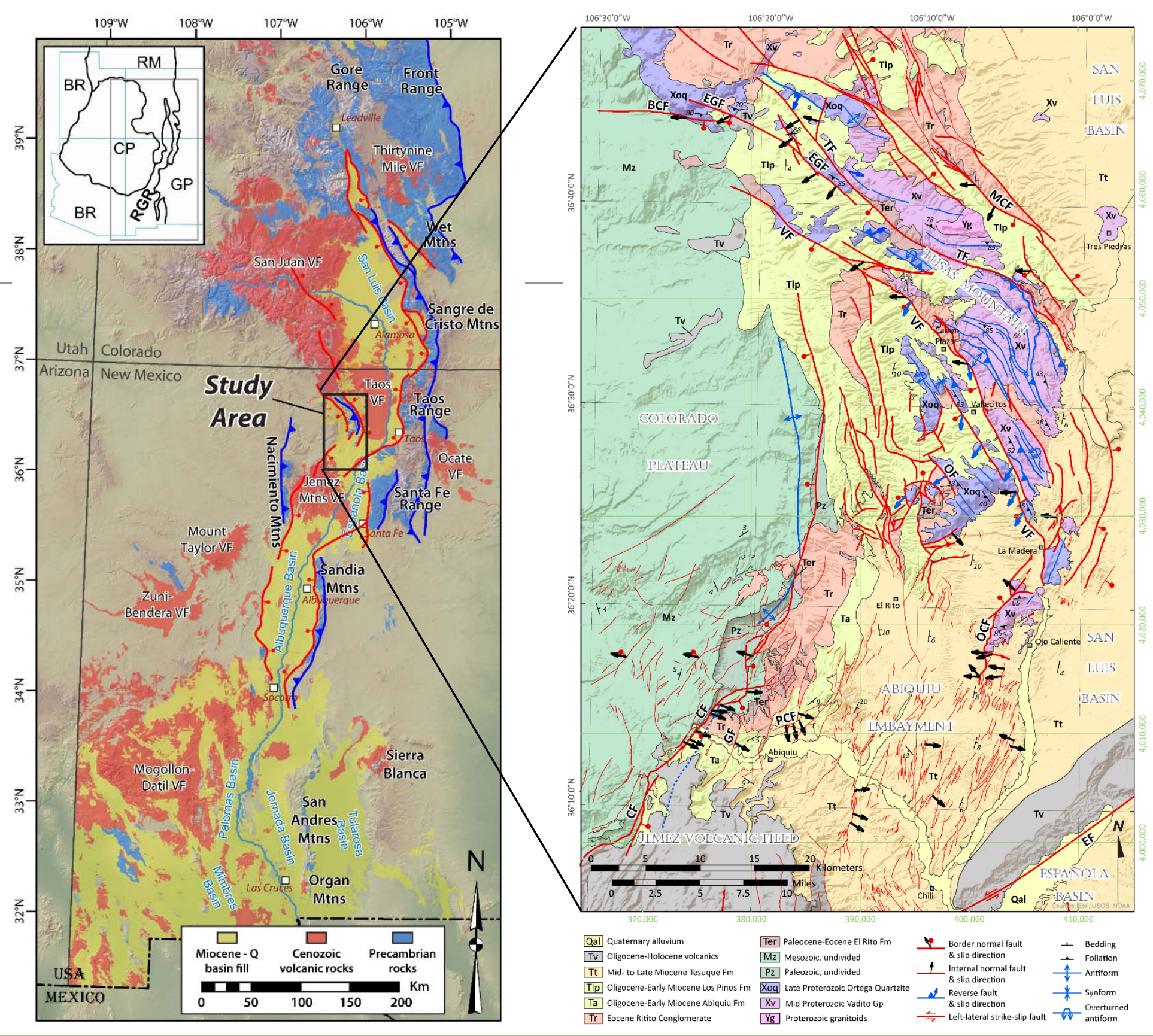

(modified from Ricketts et al., 2016, GSA Bull) 


\section{Conclusions}

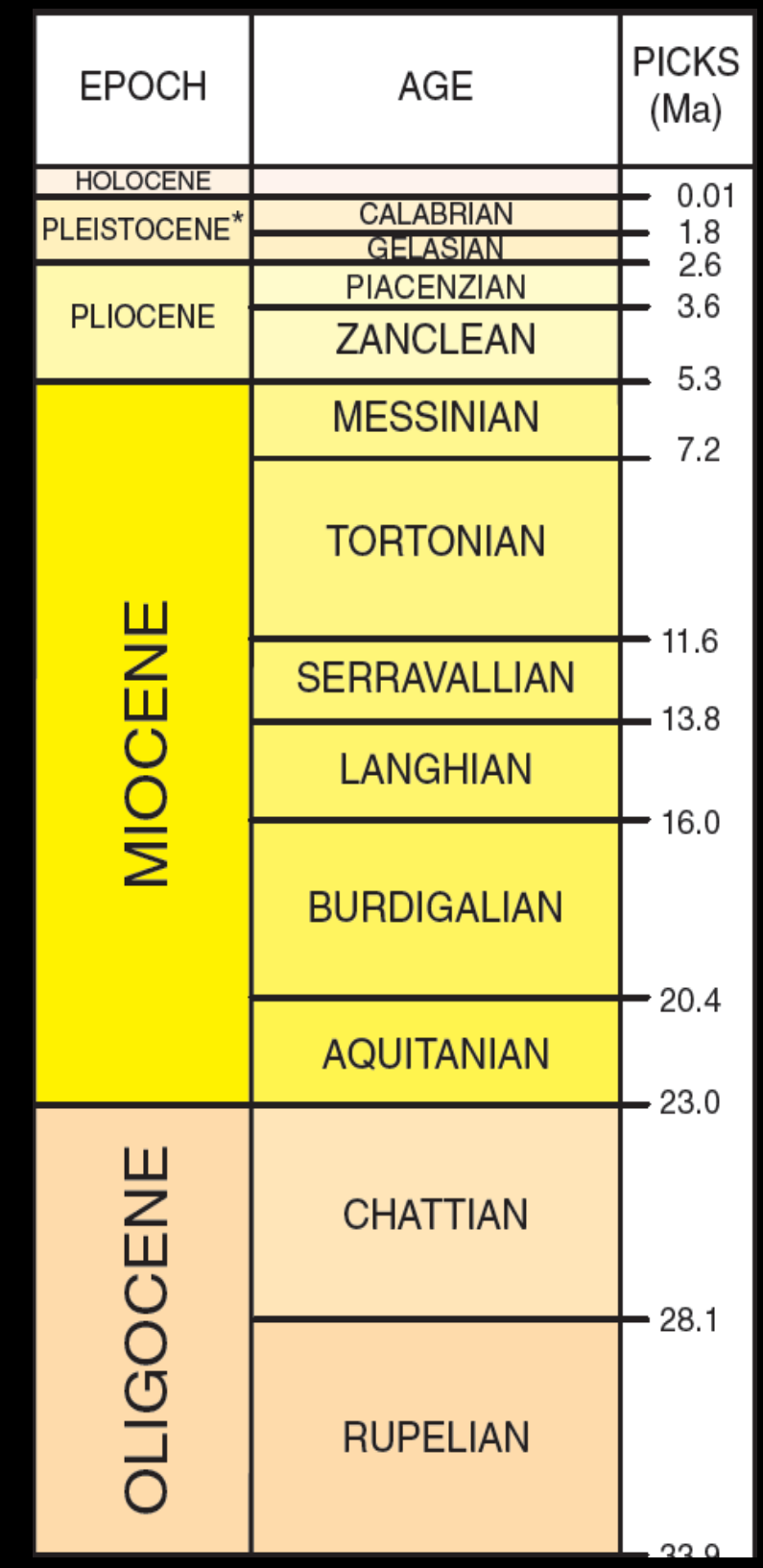

Kinematics
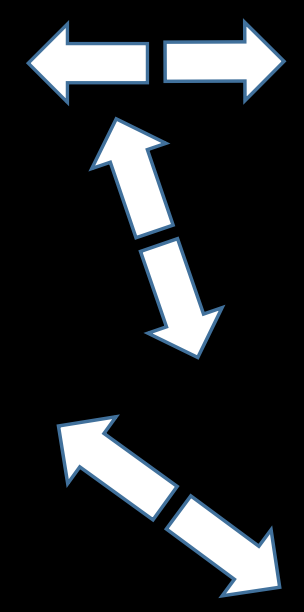

.

fault growth \& linkage

Orthogonal extension in Tusas; reactivation

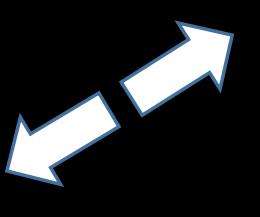

Near E-W extension

\section{Mechanism}

Small-scale convection

Loading of the Jemez VF
Pacific-North America

oblique motion
Oblique extension in Abqiuiu

\& Tusas;

Local N-S "extension" 


\section{Tusas segment}
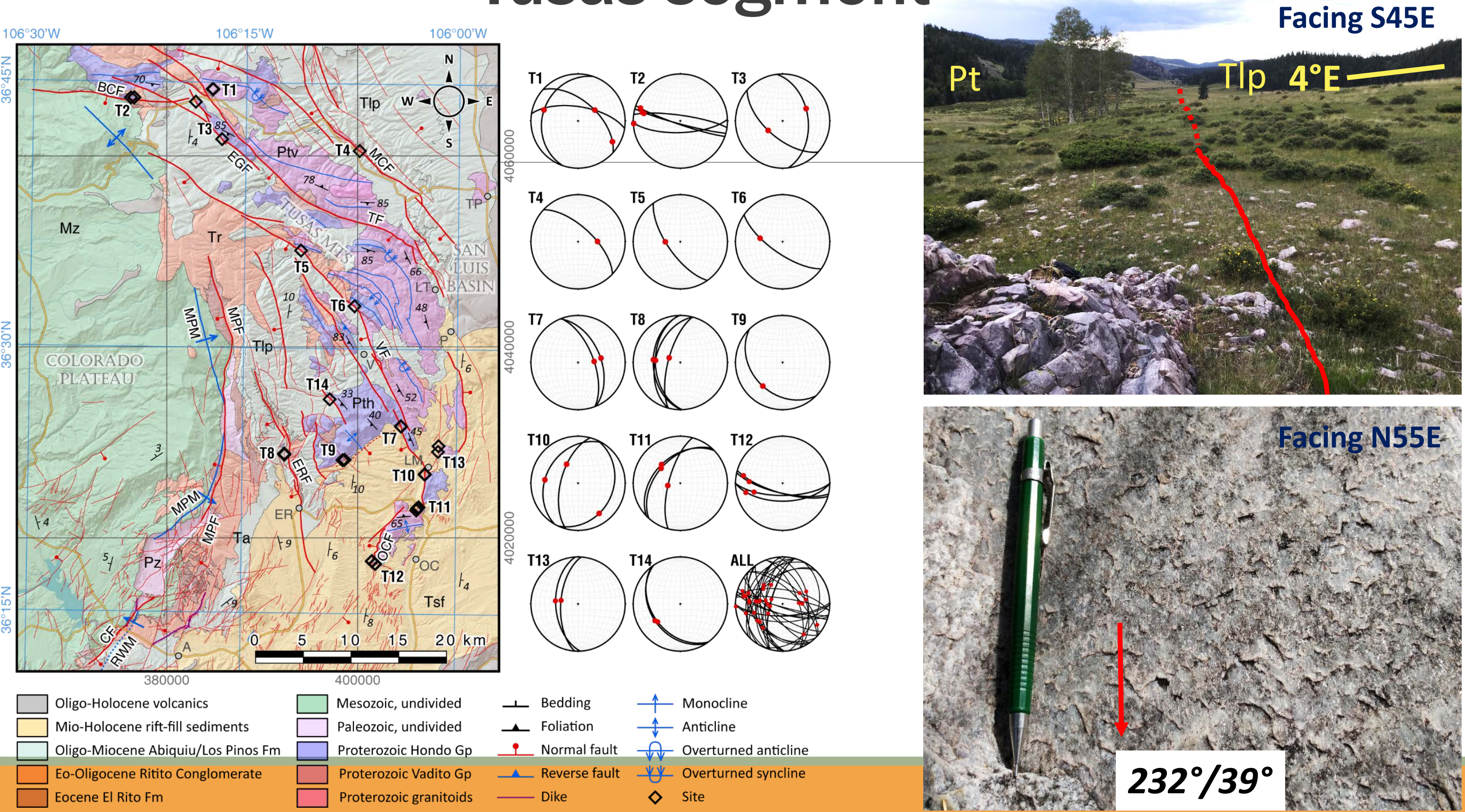
工 Bedding $\uparrow$ Monocline
ـ Foliation $\uparrow$ Anticline
- Normal fault Tि Overturned anticline
__ Reverse fault $\forall \forall$ Overturned syncline

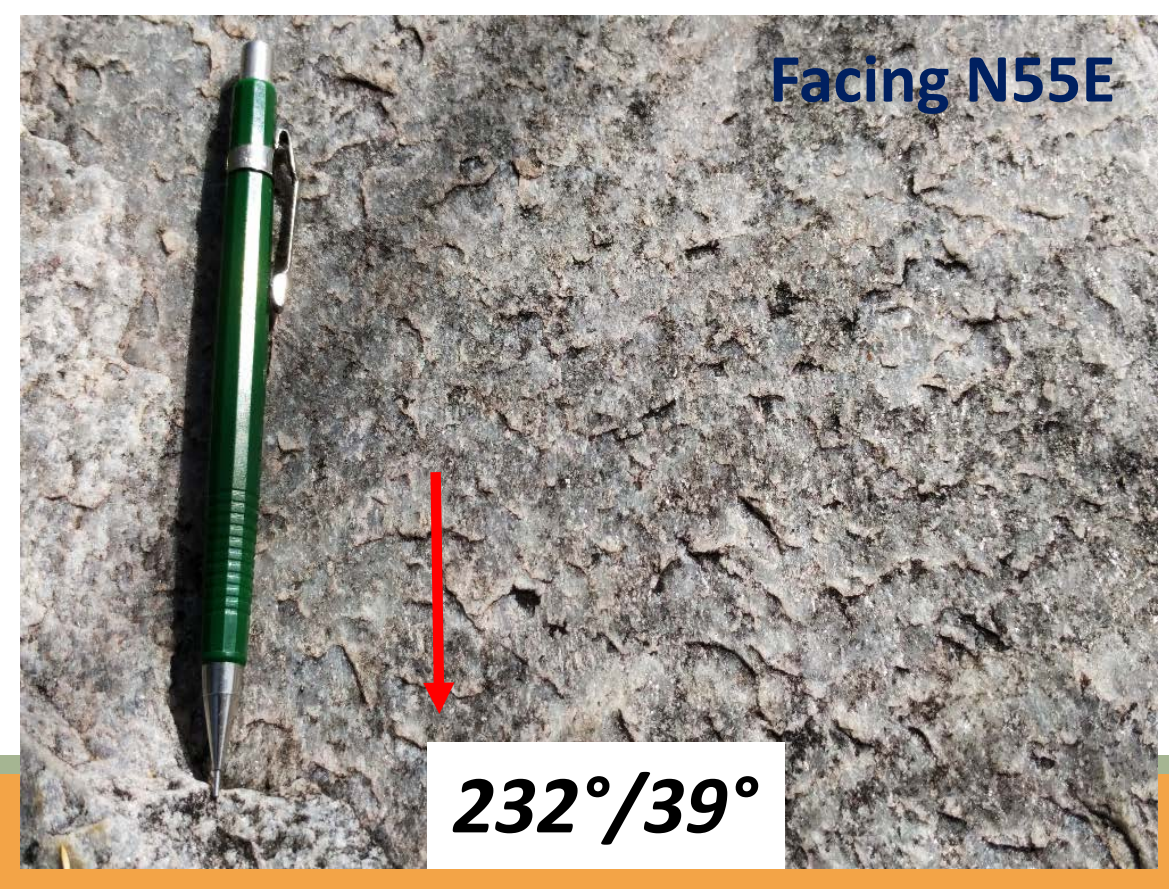




\section{Tangent-Lineation Diagram}

\section{Rake Rose Diagram}
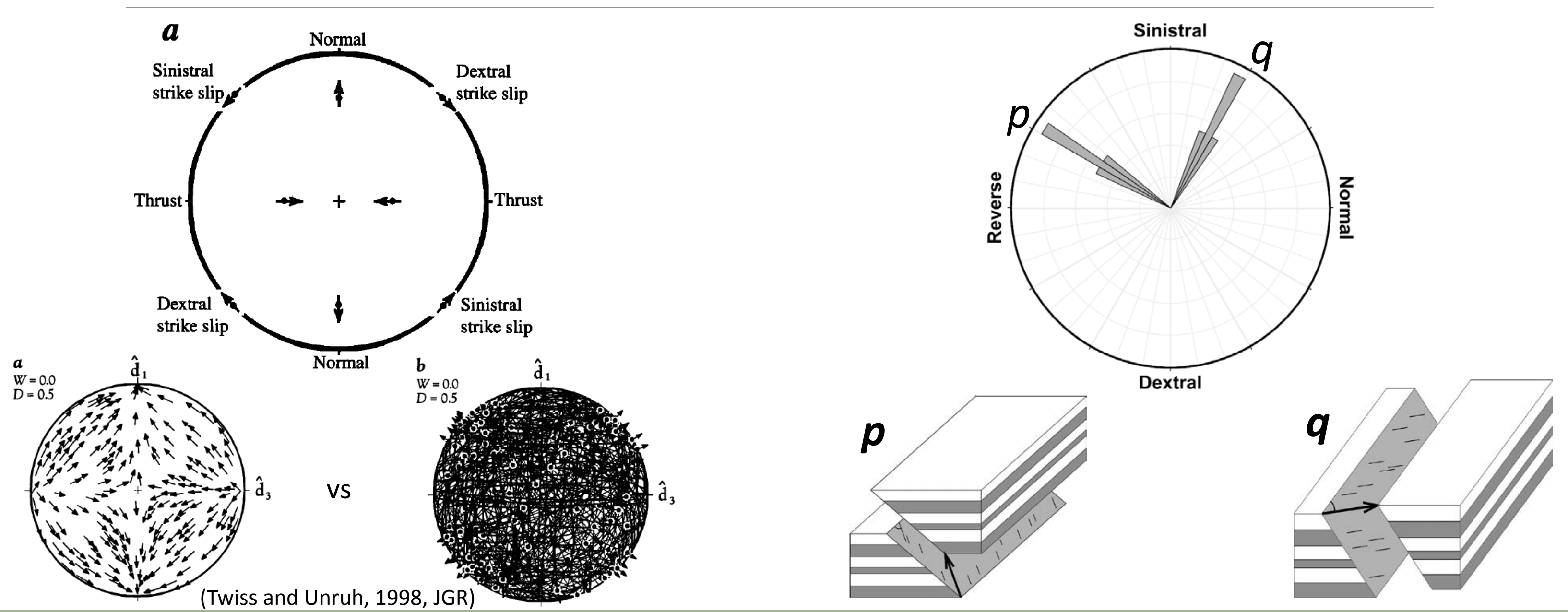


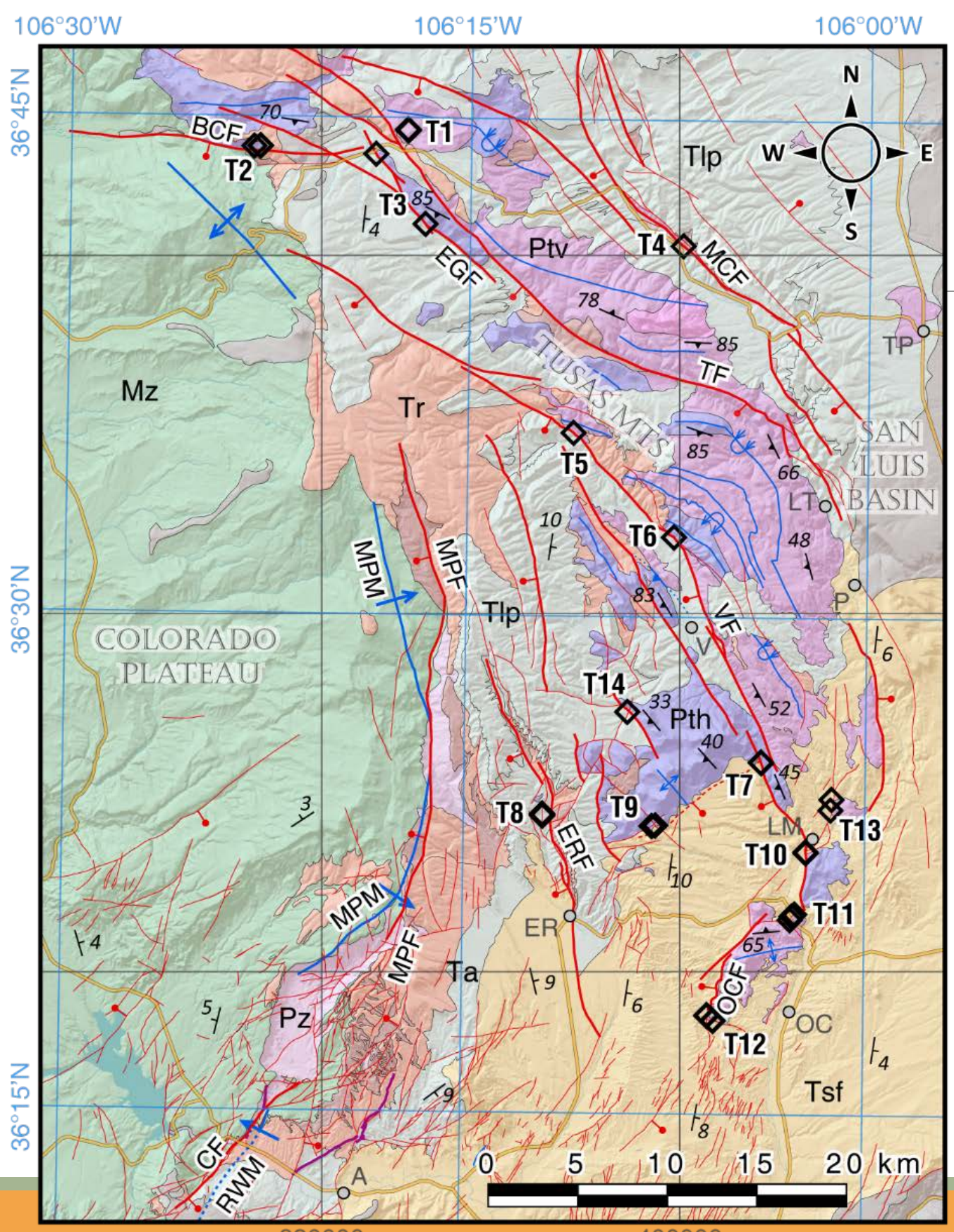

\section{Tusas segment}
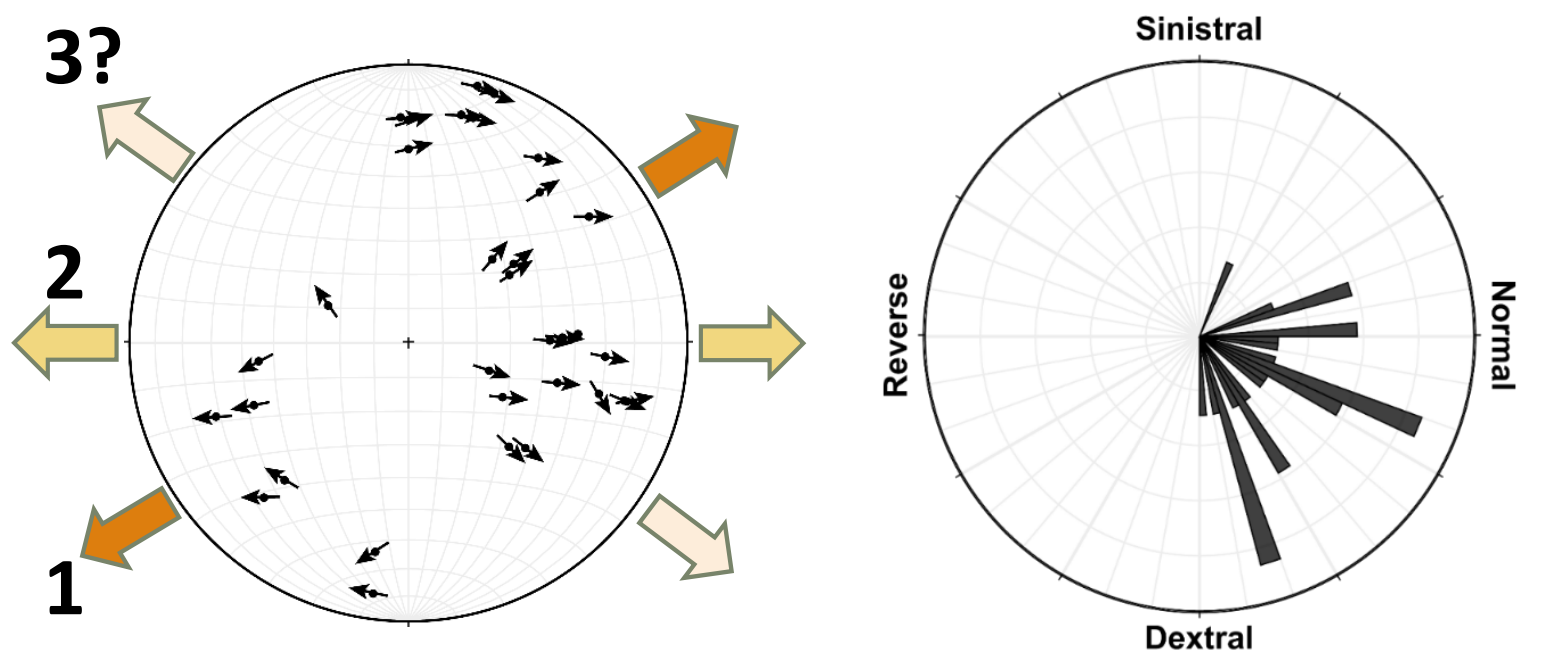

Multi-direction extension:

$1, \mathrm{~S}^{\circ} 5^{\circ} \mathrm{W}$, near orthogonal rifting

2, near E-W, oblique (dextral-normal)

$3, \mathrm{~N} 50^{\circ} \mathrm{W}$ (?)

$75^{\circ}$ clockwise rotation of the extension orientation 
Cañones F.

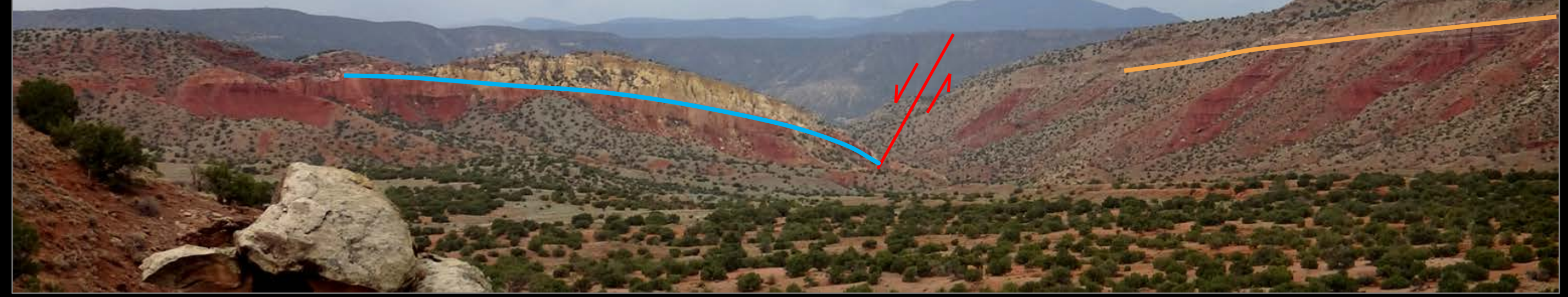

\section{Mogote F.}

$\odot / \otimes$

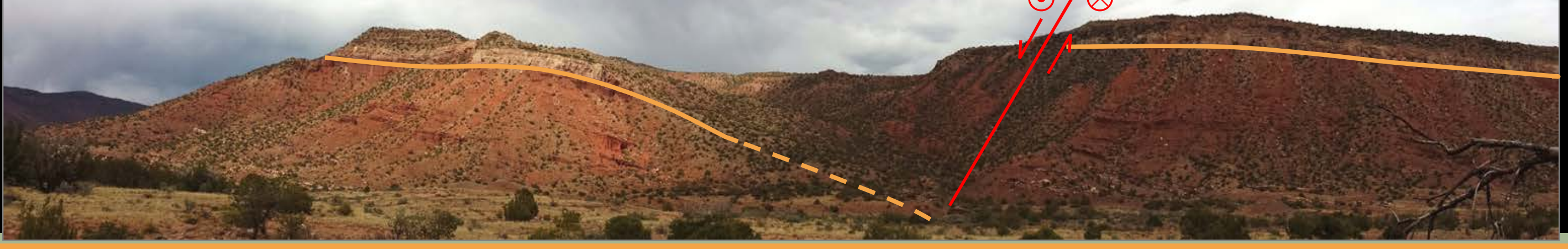




\section{Abiquiu segment}

\section{3}
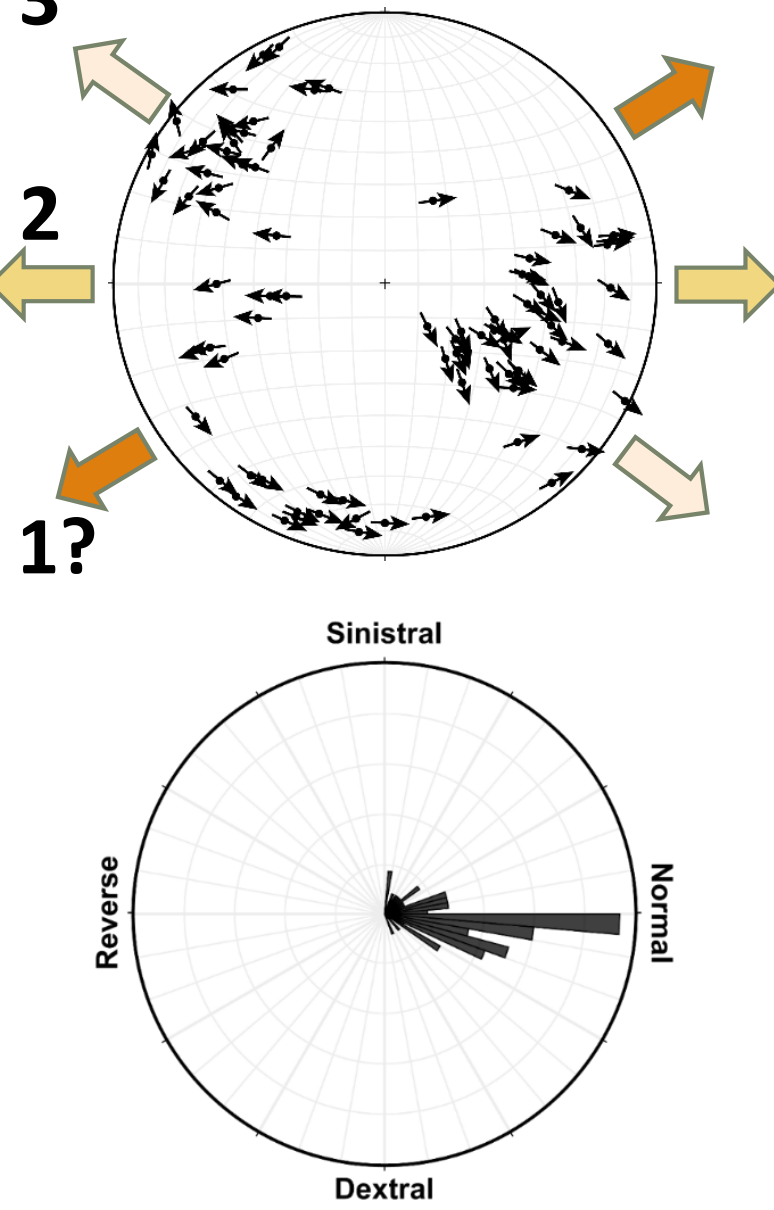

$N=62, n=266$
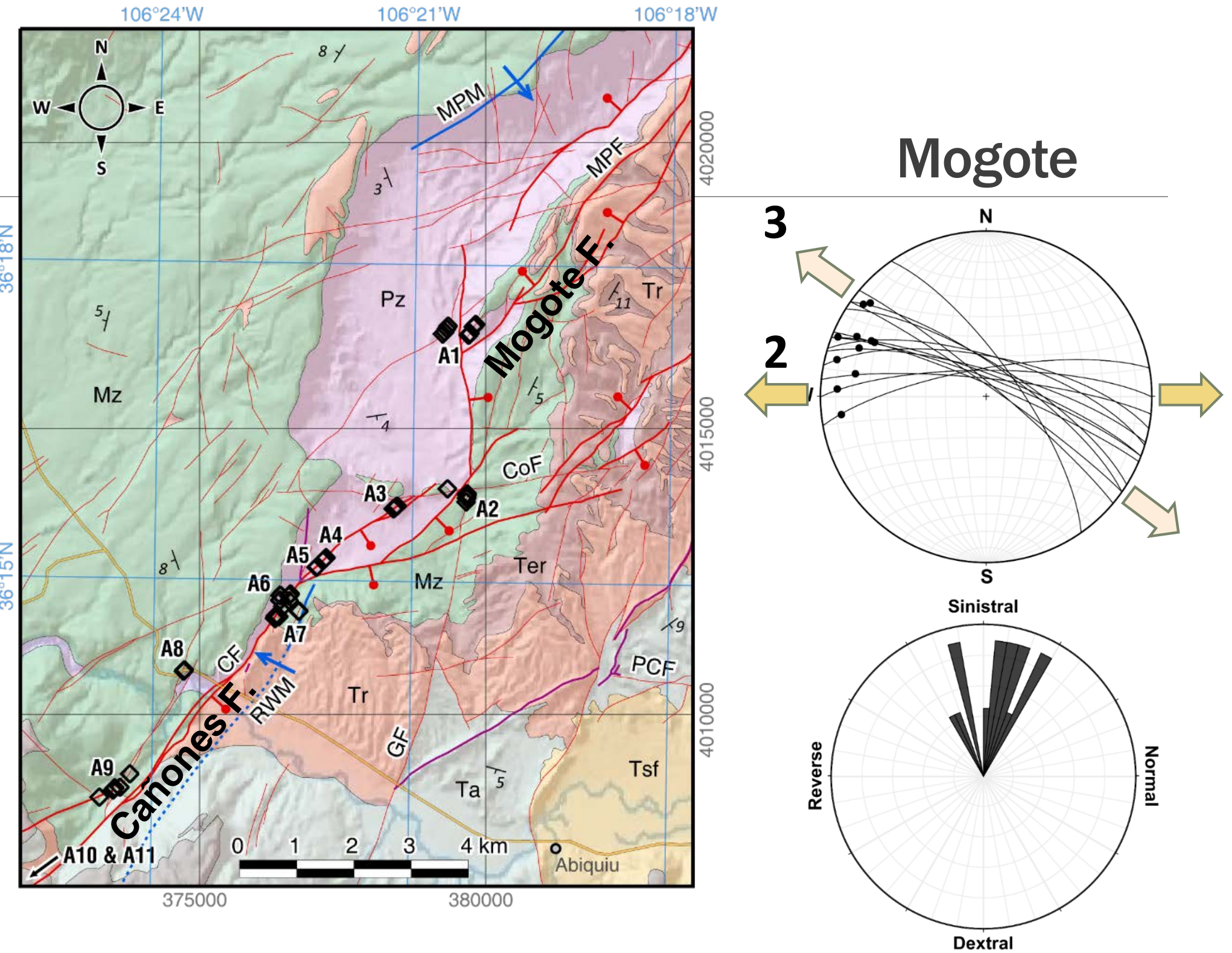

$N=14, n=33$ 


\section{Internal faults in the Abiquiu embayment}
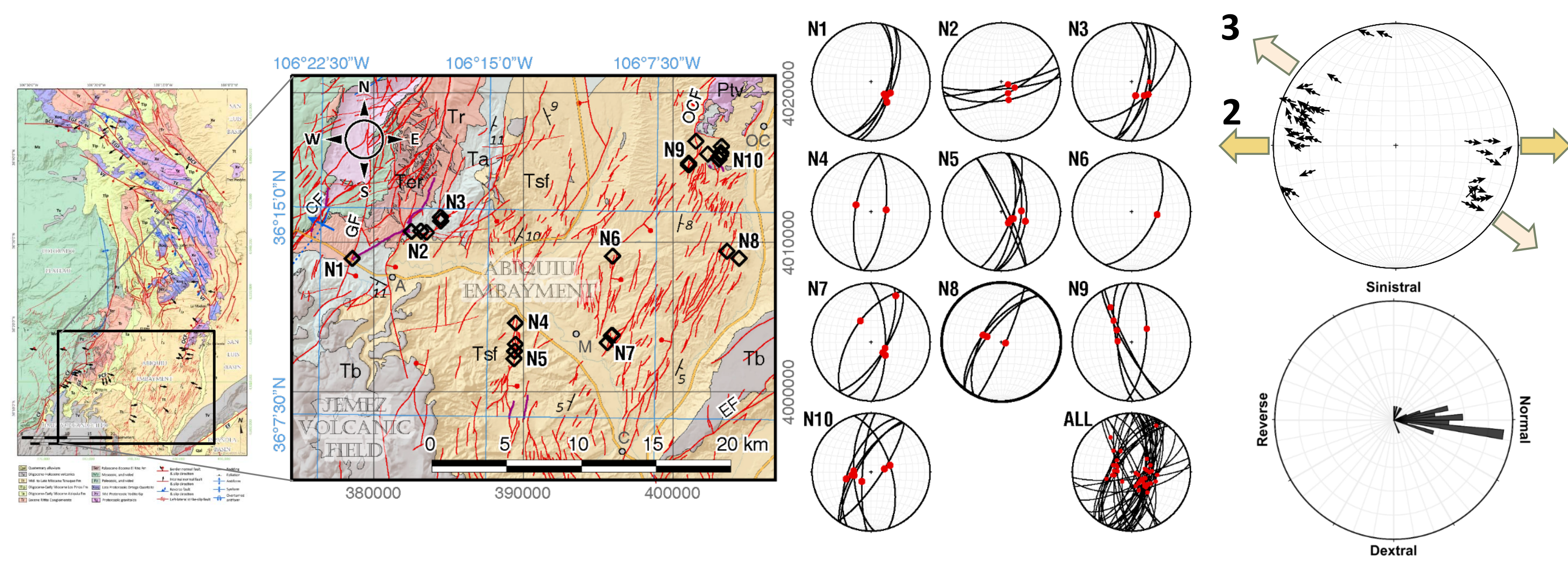

$N=42, n=250$ 


\section{E-striking normal faults}

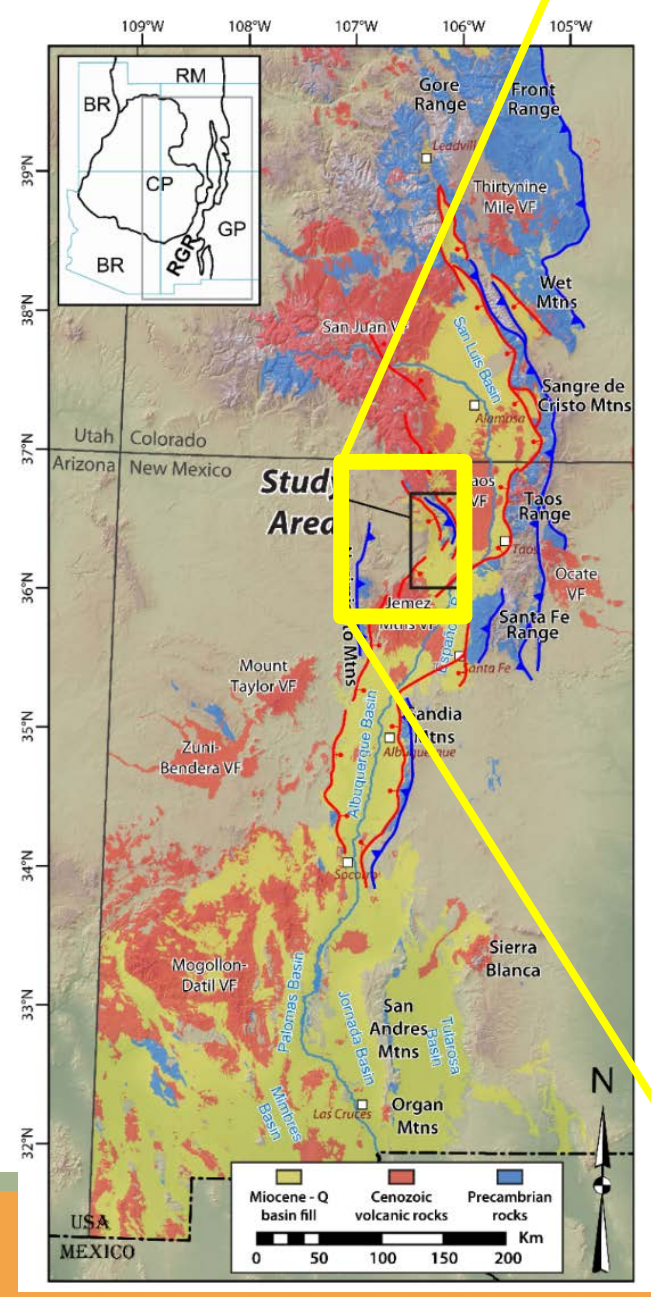

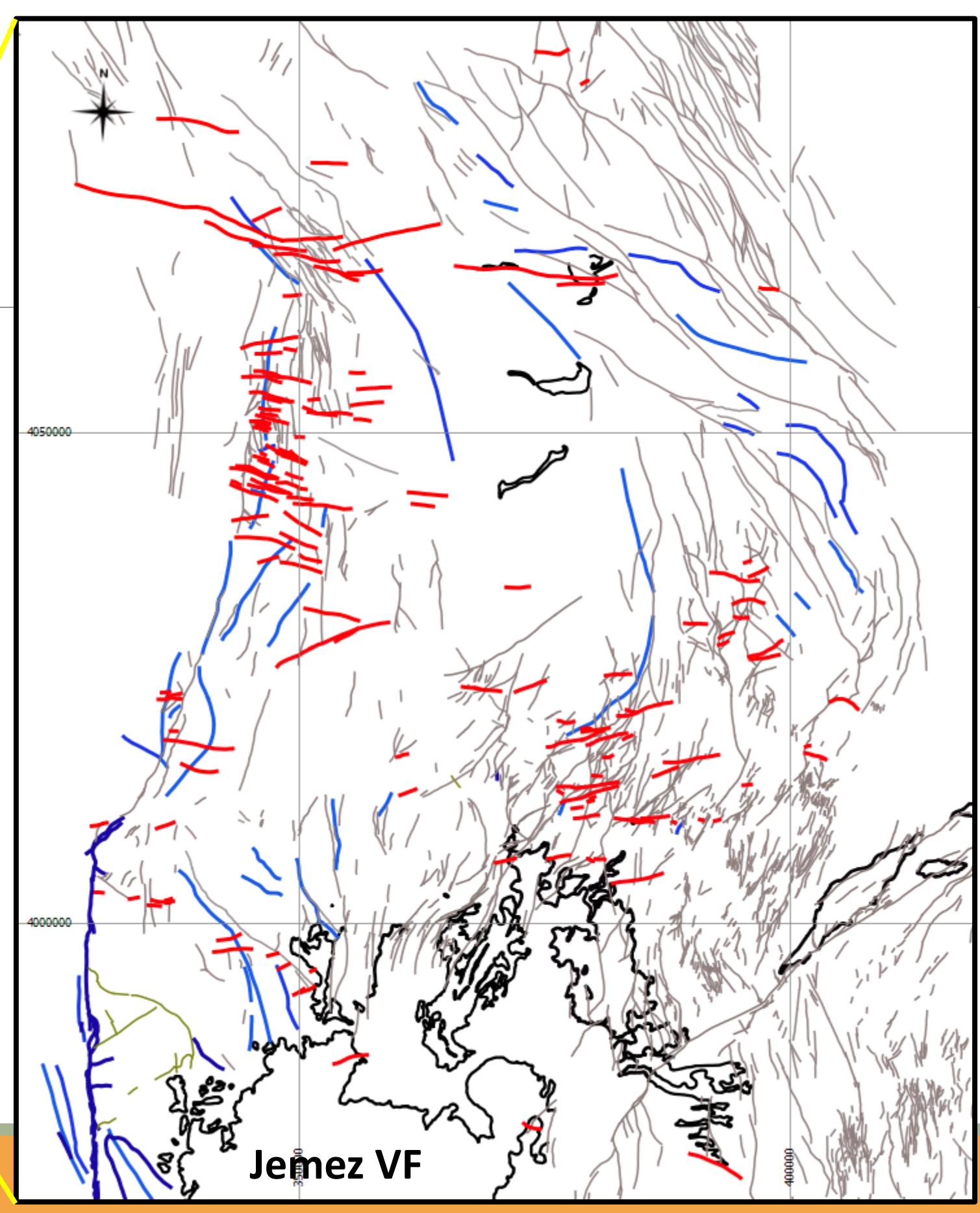




\section{"Slip re-orientation" in oblique rifts under the influence of a crustal-scale weak zone}

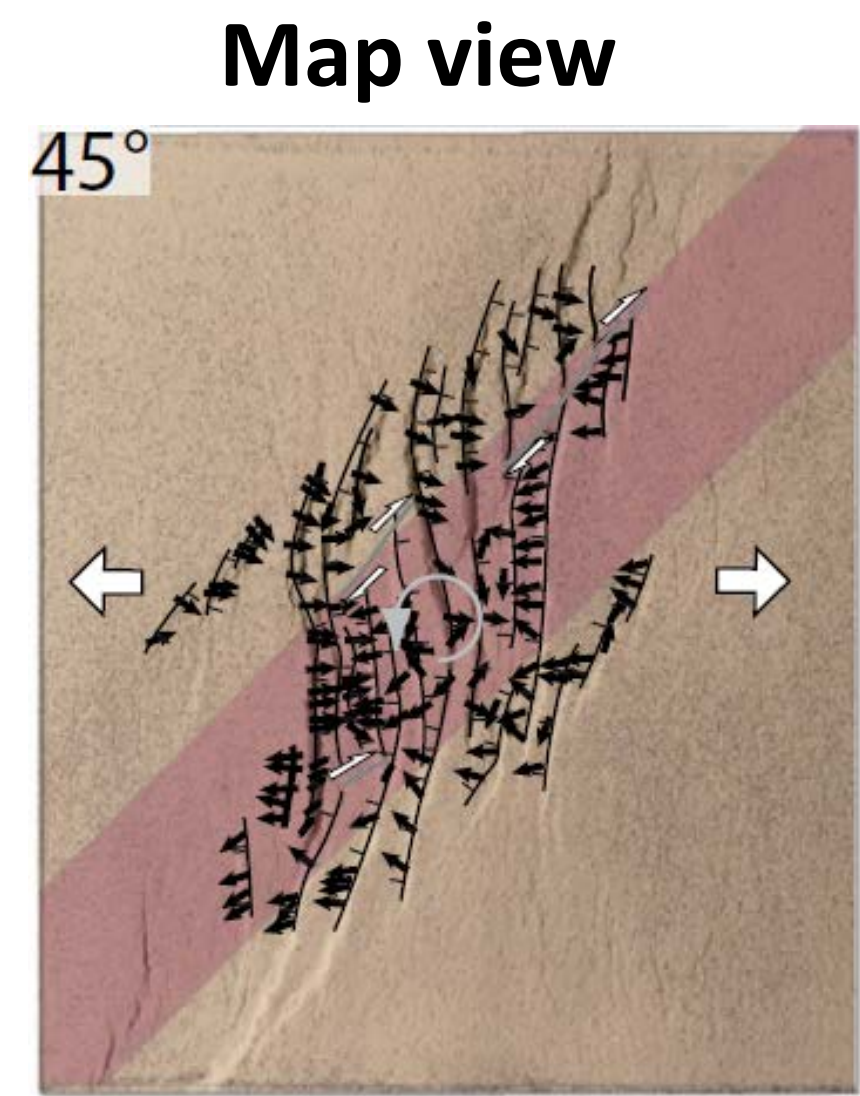

Border F. Internal F.
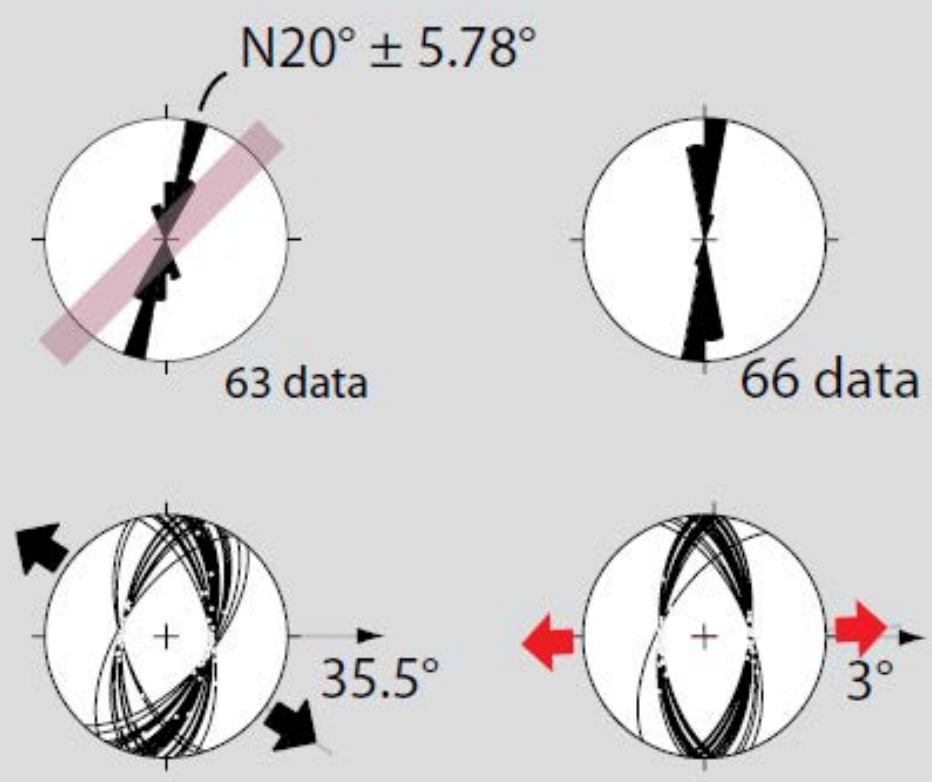

rake: $82^{\circ} \mathrm{S}$

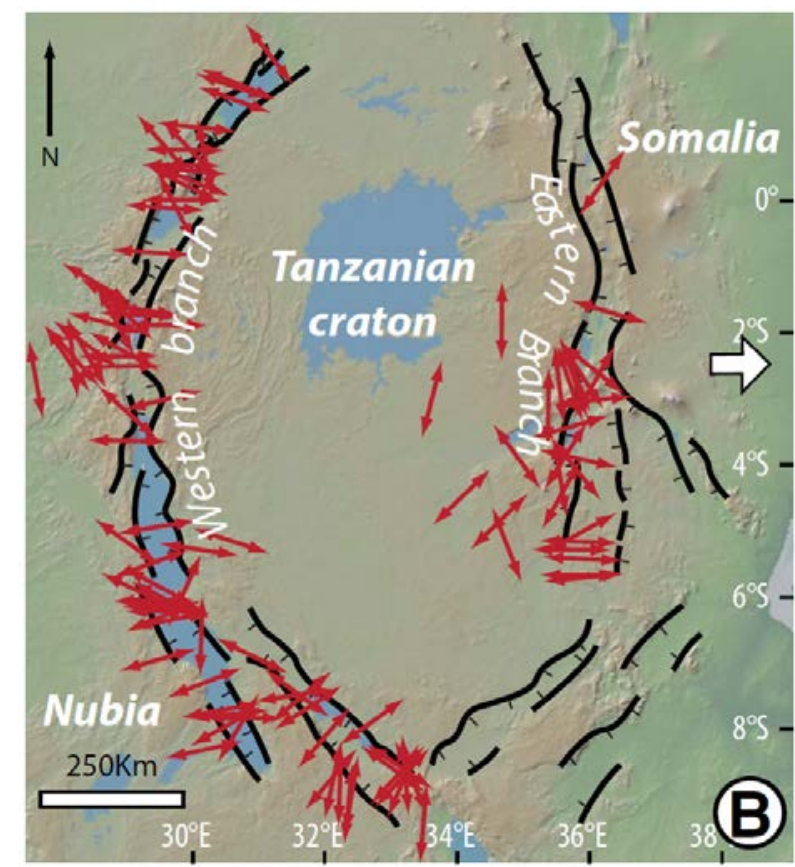

Malawi

Rift

W31 W32

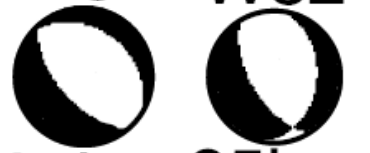

$27 \mathrm{~km} 25 \mathrm{~km}$

W33 W34

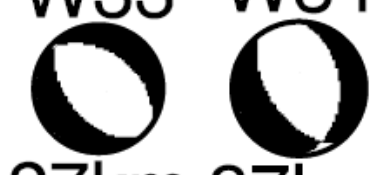

$27 \mathrm{~km} 37 \mathrm{~km}$ 


\section{Slip re-orientation model vs. observation}

Map

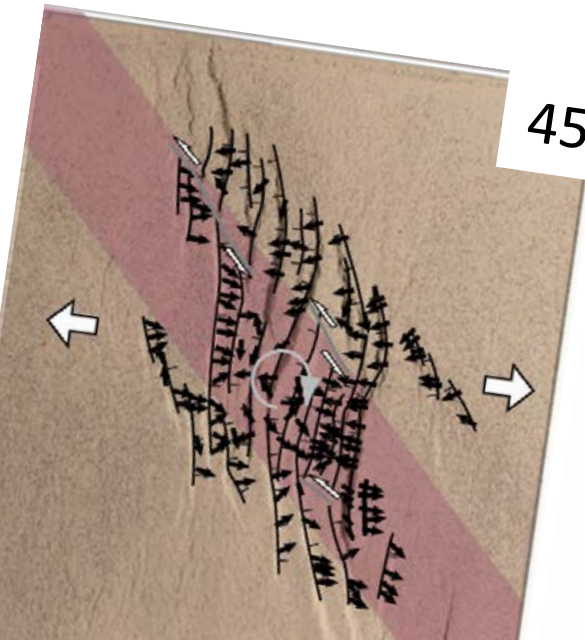

$30^{\circ}$

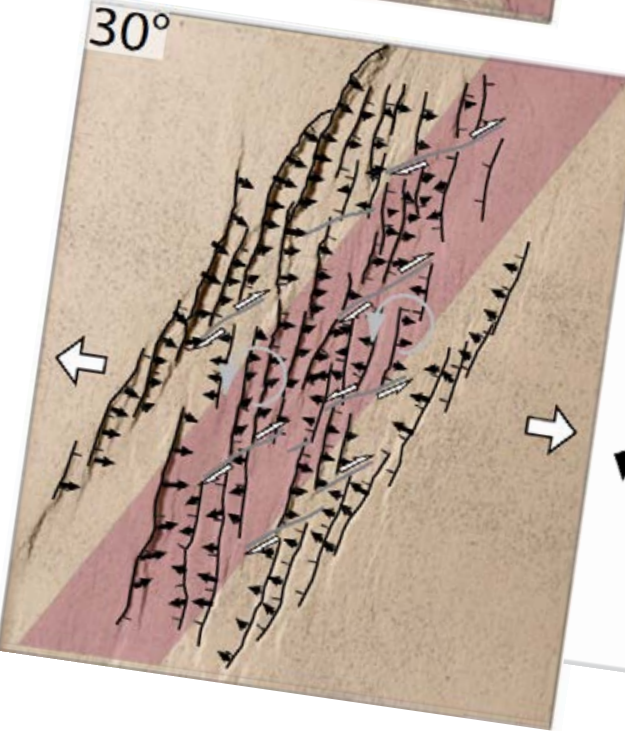

\section{Border}

Internal
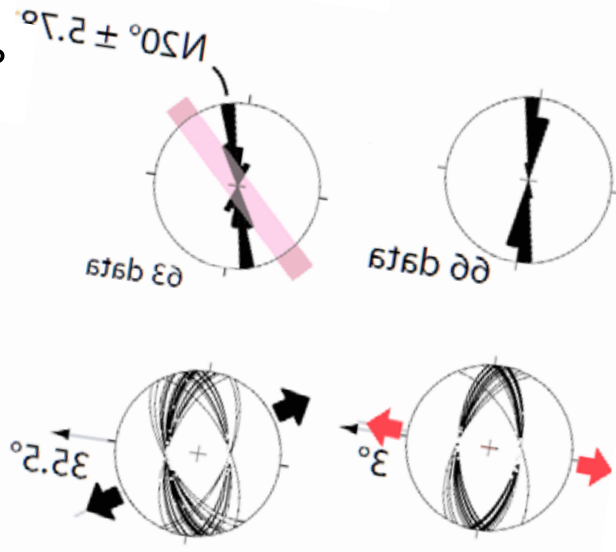

a
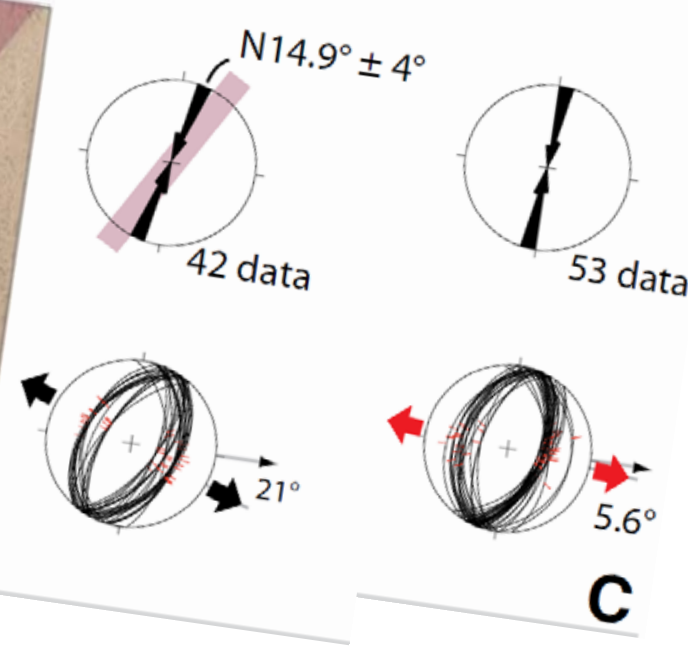

Border

Internal

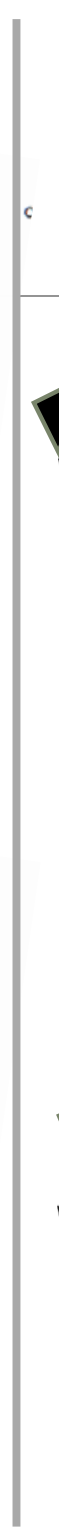

Tusas

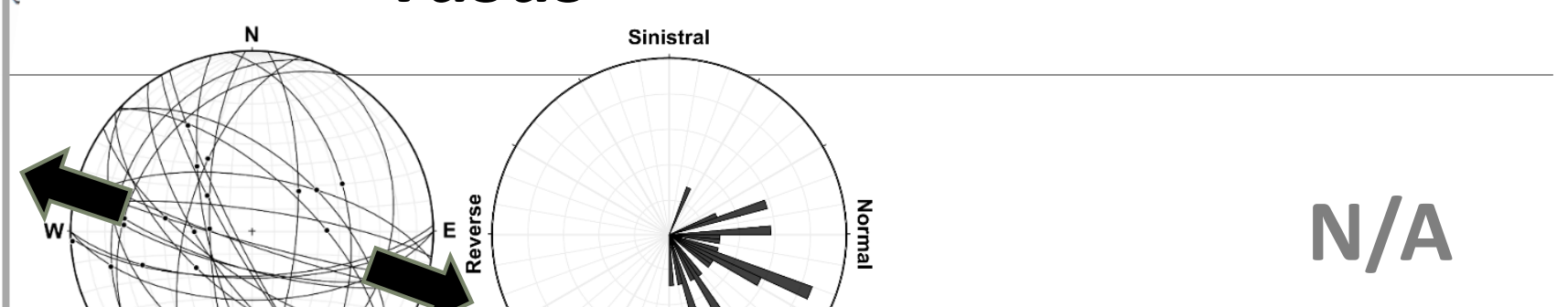

(modified from Philippon et al., 2015, Geology) 


\section{Tusas segment}

- no slip re-orientation during oblique (WNW) extension

- re-oriented strain paths not yet exposed

- higher friction (magma-poor?)

- strike of reactivated fault not indicative of extension orientation

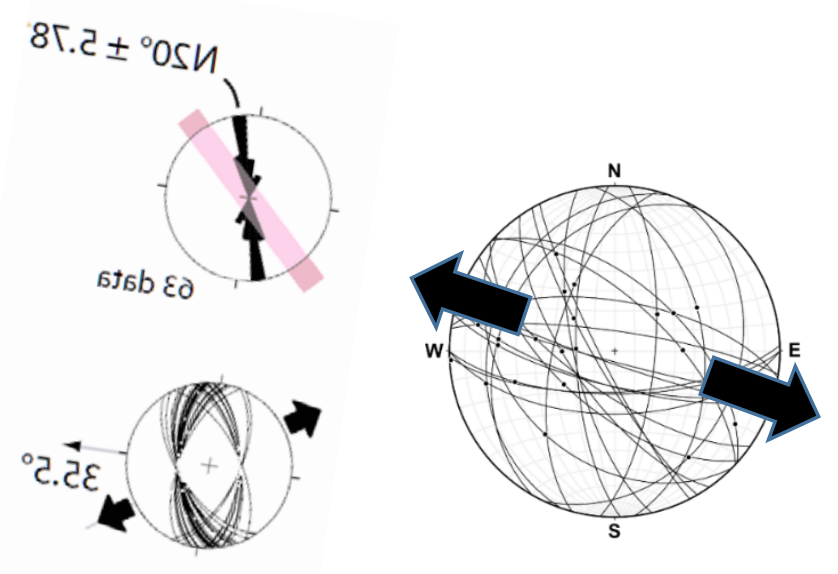

\section{Abiquiu segment}

- slip re-orientation may have occurred during WNW extension

- weak crust underneath

- elevated pore fluid pressure

- more evolved stage?
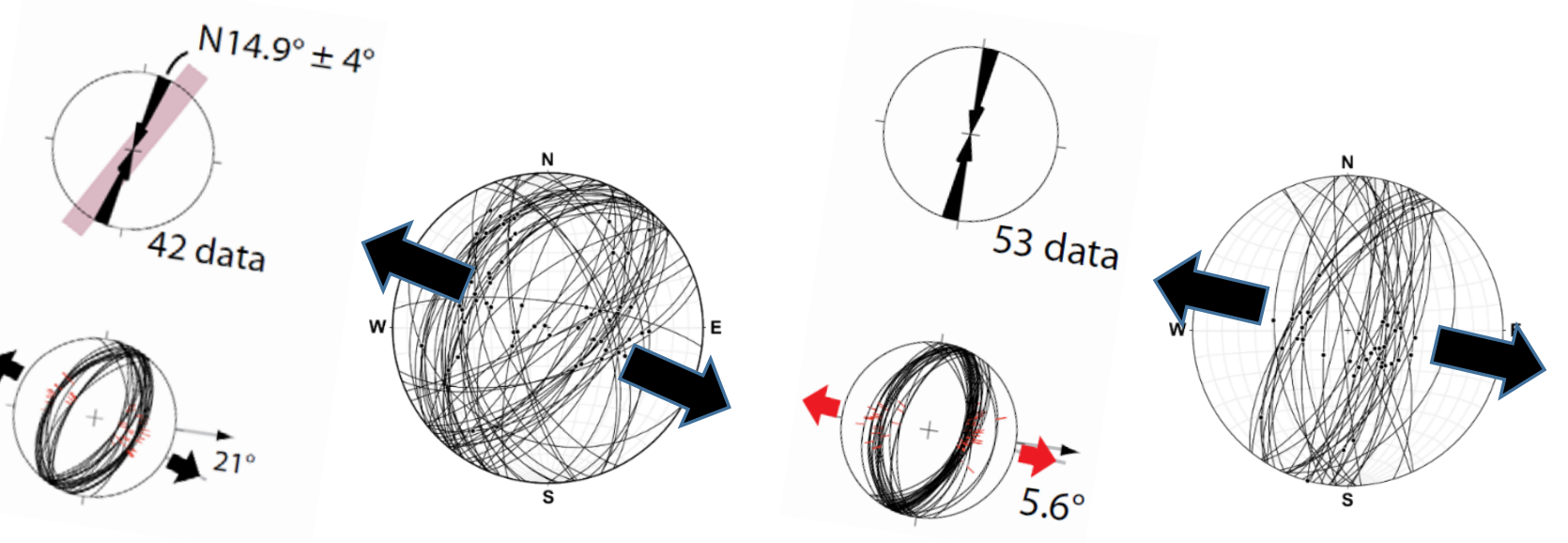


\section{Conclusions}

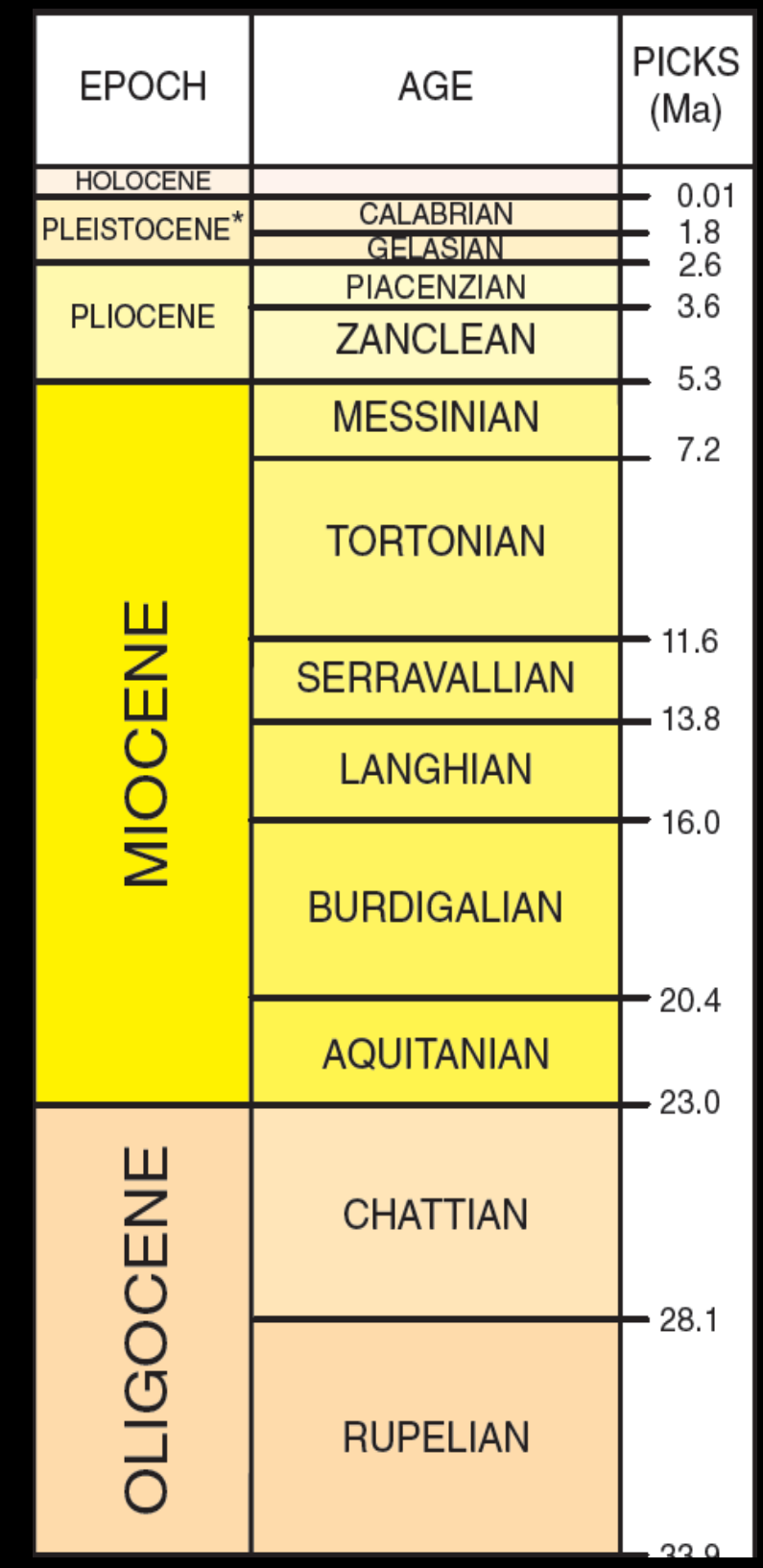

Kinematics
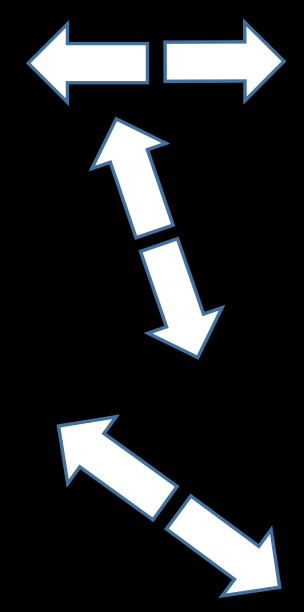

.

fault growth \& linkage

Orthogonal extension in Tusas; reactivation

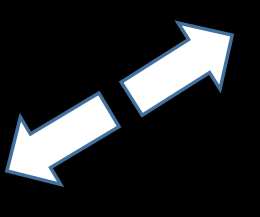

Near E-W extension

\section{Mechanism}

Small-scale convection

Loading of the Jemez VF
Pacific-North America

oblique motion
Oblique extension in Abqiuiu

\& Tusas;

Local N-S "extension" 
Thank you! 